\title{
Reconstruction of the Old Bridge of Mostar
}

\author{
M. Popovac
}

The Old Bridge of Mostar was built in 1566 by Hajrudin, a student of Kodza Mimar Sinan, the greatest Ottoman architect. It is a stone bridge of very slender and elegant shapes: its profile and its skyline are so thin and so high over the river waters that it is hard to believe that such a structure could be made out of huge stone blocks.

The Bridge was destroyed in November 1993 by shelling during the recent war events. Its reconstruction was one of the biggest and most complicated projects involving UNESCO, The World Bank and many local and international experts. The task was to build a New Old Bridge - precisely the same in all details as the Old one. After many studies, tests and shape determinations, the project was completed and the actual reconstruction work could begin. Ancient techniques and methods, original materials and a perfectly reconstructed shape gave this Bridge its new life in post-war Mostar.

Keywords: old, bridge, Mostar, Maja, Popovac, Bosnia, Herzegovina, reconstruction, UNESCO, World Bank.

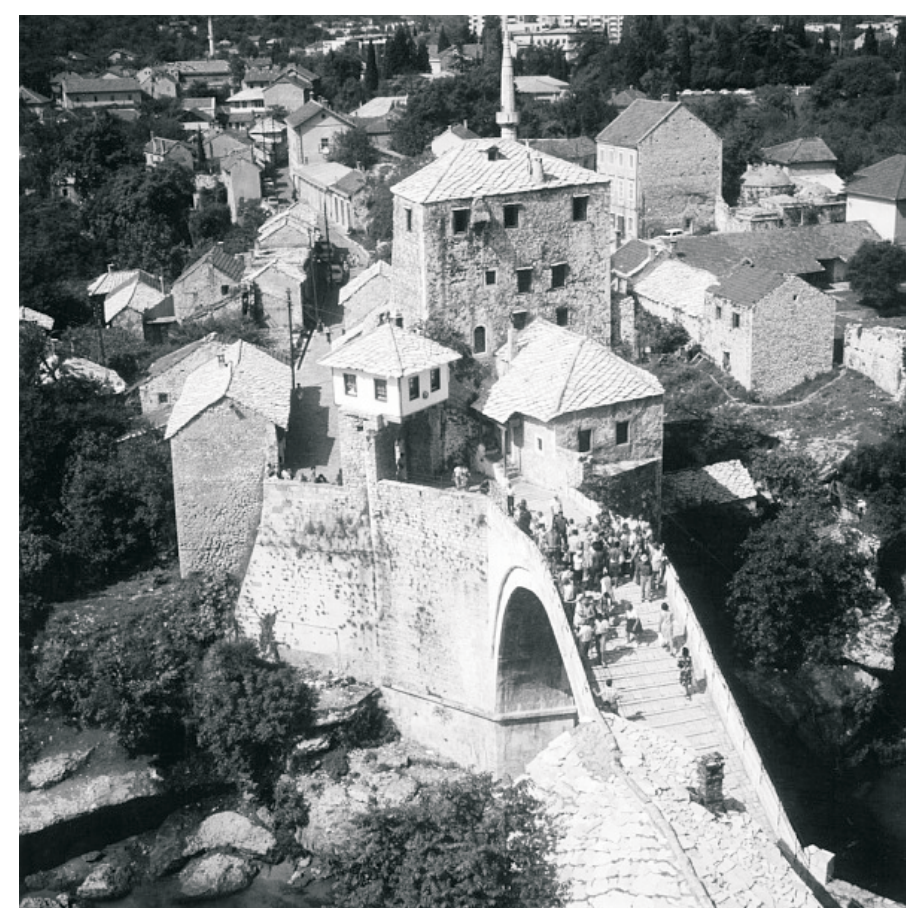

Fig. 1: Bridge in the 1980s

\section{History}

Stari Most (or Old Bridge) is the most recognizable symbol of Mostar. Sadly, most people only know Mostar from the destruction of Stari Most in 1993 during the War in the Balkans.

The oldest written testament to the existence of medieval Mostar dates back to the 15 th century, prior to the invasion of the Ottoman Turks. The first written documents about the city date from 1452. In report to the city council of Dubrovnik about the rebellion of the ruler's son, who took several towns into his possession, including the town with "Duo Castelli al ponte de Neretua”.

Soon after its foundation, Mostar have taken over the primate of Blagaj, an old city situated under the Castel of the Hercegovina region founder - Herceg Stjepan Radivoj Gost. Mostar developed into a strategic and commercial hub and became the meeting point of roads from the sea connecting the south to the north and the eastern regions to the western regions.

The first medieval bridge in Mostar was a wooden suspension bridge which was very unstable and of fragile construction. In the 16th century, Sultan Sulejman the Magnificent ordered the construction of a new bridge in Mostar. From the reports of Hadzi Kalfa, the bridge was completed in 1566 which, coincidentally, was the last year of Sulejman's reign.

There are no documents about the building procedures, the site organization or the construction. We think that the centering (semi-circular scaffolding) was made of wood, and that the bridge was built in a short period of time - maybe even in a single dry season. There is also a tale that Hajrudin escaped to the mountains before the centering was released, because he was afraid that this slender will collapse together with its support. 
Historical evidence has shown that the two towers were in existence in 1452 (some writers describe them as much as 84 years before the bridge). Research indicate that the towers where from the era of the medieval Bosnian State and later modified for the needs of the Ottoman Turks.

The first renovations of the towers were made during the reign of Mehmed II el-Fatih who also carried out renovations on the old wooden bridge existing at that time. During that time the whole town of Mostar was converted into a fortification.

First sign on the bridge, dating from 1676, mentions no repair work on the bridge, but however there is evidence that repair work was in fact carried out at that time. The second sign mentions that repairs on the bridge were completed in 1150 (1736-1737).

During the Austro-Hungarian occupation of the Mostar area many renovations were made. The sloping ground on either side of the bridge was raised by $80 \mathrm{~cm}$. in order to deal with the traffic problems. The path on the bridge was also increased and re-surfaced. To adapt to the current situation, the main streets leading to the bridge were raised, and the elevation of the entrance doors of the bridge were increased. After World War II, reconstruction around the bridge area continued and the remains of the Austro-Hungarian interventions were removed. During the Austro-Hungarian period damaged stones on the bridge were repaired using cement mortar, which was a poor solution as the mortar left stained dark spots on the bridge.

During World War II plans were made to destroy the Old Bridge, but fortunately these plans were discarded. However, there was some damage, due to mine holes, and even after repairs of the mortar, water could penetrate the structure leading to further damage. The situation was considered very serious, and restoration began in 1955. Supports were restored on either side of the bridge and damaged walls and empty cavities were fully repaired. The restoration was completed by the end of 1965 . The second stage of restoration involved the arch of the Old Bridge, using the injection

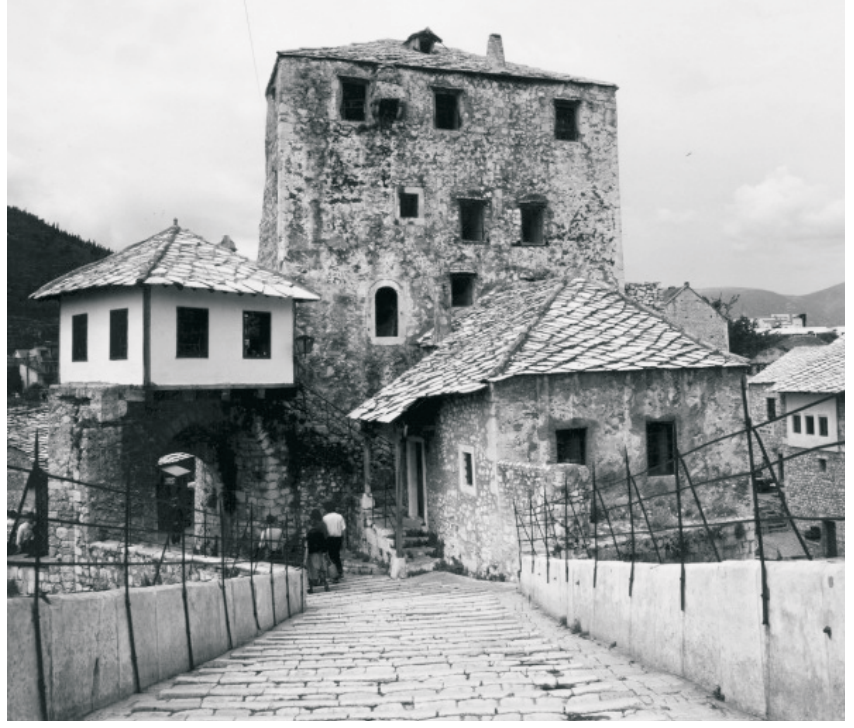

Fig. 2: Bridge in the 1980s 1981 project - site plan method, with a special mixture of $82.50 \%$ cement, $15 \%$ mixture of stone flour composed of limestone tenelija and $2.50 \%$ bentonite. The volume of this mixture required for the repairs totalled 7 cubic metres, which gives us a good indication that the arch (vault) was severely damaged, and cracks were also appearing in the stone and mortar joints. At this time, damaged stones on the vault as well as on the façade were replaced, and cavities of cement mortar were removed and replaced with a special mixture that blended in with the colour of the tenelija stone.

Shortly before the war, some experiments with silicone emulsion were made, but these had no effect apart from leaving ugly traces.

\section{Description}

The Old Bridge of Mostar (Stari Most) was a stone bridge of very slender and elegant shapes: its profile and its skyline were so thin and so high over the river waters that it was hard to believe that such a structure could be worked out of huge stone blocks. Built in tenelija stone, it was of a light colour tone, bright and changeable during daytime, depending on the colours from the sun.

The bridge was mainly conceived as a functional structure, connecting the two banks of the river: it probably did not originally have any additional ceremonial and monumental meaning, and its design was quite influenced by the morphology of the site, which is totally matched by its abutment walls. The whole monumental complex, including the adjacent fortification towers, is totally part of the site, castled on the rocks and winding the banks, it is not the result of a single design work, but of a development over the course of time, that has followed, and historical events and the need to protect and preserve the bridge, that has marked the town even provided its name "Mostar".

The bridge had few esthetic devices and no ornamental element; its architectural beauty and value were to be found in the simplicity and in the essentiality of the structure: the shapes of the bridge were not linked to any time, to any style or any fashion, in but the bridge of Mostar has always been admired as symbol.

Two cornices, only, with an angled section profile, ran on each elevation and met at the keystone with a refined balance between tangency and jutting out: both of them had a protective function against rain waters, and they marked different structural elements of the monument, being part of it and not pasted. A bigger cornice, on each side, determined the level of the bridge arch springer, prosecuting upstream and downstream along the abutment walls.

The stone surfaces were neither polished nor regular: they were perfectly cut and hand worked, but characterised by frequent ordinary structural inaccuracies which revealed their materiality and the fact that they were made of stone. Of more than one thousand stone blocks, there were no two elements of identical dimensions, and even the arch voussoirs were all different, with remarkable variations, due to the random, naturally-determined, availability of stones in the quarry. Undoubtedly, most of the architectural beauty of this monument lay in the refined tuning in the globally compact appearance of the structure, caused by the thin joints of the masonry, and the unforeseeable and fragmentary close-view appearance 
due to the small imperfections of stone blocks in the assembling of different shapes and sizes.

The one-span bridge had an intrados curvature that was almost circular, with the centre adequate way approximately $296 \mathrm{~cm}$ lower than the east springer level; but the circle shape may be not an adequate way to describe the curvature, which was modified at the level of the imposts to better match with the straight profile of the abutment wall, and was slightly raising at the key stone level. The exact original shape of the curvature vas desturbed by irregularities that may have been caused by settlements and by ordinary construction imperfections.

The main dimensions of the bridge were as follows: the span was of $2871 \mathrm{~cm}$ on the north side and of $2862 \mathrm{~cm}$ on the south side and the rise of the arch was approximately of $1206 \mathrm{~cm}$. The measurements were clearly often variable, and impost level of the bridge on the west bank was approximately $12-13 \mathrm{~cm}$ higher than on the east bank.

The load bearing arch had a depth of about $395 \mathrm{~cm}$ and an height of $80 \mathrm{~cm}$, and was composed of 111 rows (a number which was probably planned and not randomly obtained), and the rows contained between 2 to 5 voussoirs, (normally 3-4). The voussoirs (arch stones) were of variable shapes and sizes, but the average stone block had the following dimensions: $40 \times 80 \times 100 \mathrm{~cm}$.

The arch and elevations of the bridge were made of tenelija stone (local limestone) and joined by mortar and metal reinforcing cramps and dowels. The use of forged iron devices to strengthen the structure was one of the peculiarities of the monument. They were assembled in various ways, they were applied almost to every element of the bridge.

The bridge arch, at the top, was considerably higher (by about $\mathrm{cm}$ 270) than the adjacent street levels. The footpath over the bridge was steep, and tilted in such a way that all the architectural elements, e.g. spandrels, parapets and upper cornices, followed these directions until the top. The spandrel walls of the bridge were divided from the arch by a stone lower cornice, that followed the arch curvature, and were limited on top by the upper cornice, of straight but tilted profile. The lower cornice stones jutted out from the load bearing arch and determined the base from which the spandrel walls started; at the same time the upper cornice was jutted from the spandrel walls. Finally, the parapets were almost aligned with the spandrel walls below them, but leaning slightly, outwards as they approached the top of the bridge, to give the optical effect of a wider footpath.

The pavement was made in krecnjak stone (hard, resistant marble-like limestone), and was characterised by transversal rib-steps to prevent slipping; the flooring was assembled on a mortar layer which, most probably, also had a waterproofing function together, with the layer below made of "terra rossa" (heated aggregates of red colour due to the presence of bauxite).

On the structural side, the bridge was quite interesting, and an analysis of the inner elements shows the level of engineering skills at the time and the clever measures taken to ensure the long life of the structure.

Main structural element of the bridge was the load-bearing arch, which was undoubtedly the part of the monument that required the greatest care and resources. The arch, due to its shape and the configuration of the dead loads above, was subjected to compressive loads. The stone blocks would have been perfectly adequate for the purpose, but additional devices were provided to strengthen the vault: forged iron dowels were inserted between adjacent voussoirs, and forged iron cramps were placed over the extrados and across the side joints. Thus each connection joint was strengthen either by mortar, or by metal reinforcements.

Over the load-bearing arch there was a masonry rib which together with the spandrel walls stiffened the whole bridge. Between the spandrel walls and the stiffening rib there were two lightening voids, which reduced the loads over the arch. Fill was wisely provided only next to the arch springers in order to stabilise the structure and the vault. The lightening voids were covered by krecnjak stone slabs, and above them there were only thin layers of aggregate nad then the pavement.

The appearance and structure of the bridge architecture were strictly related, in such a way that the inner structure could be perceived just by observing of the outer elevations, where the cornices marked the most important structural sections of the bridge.

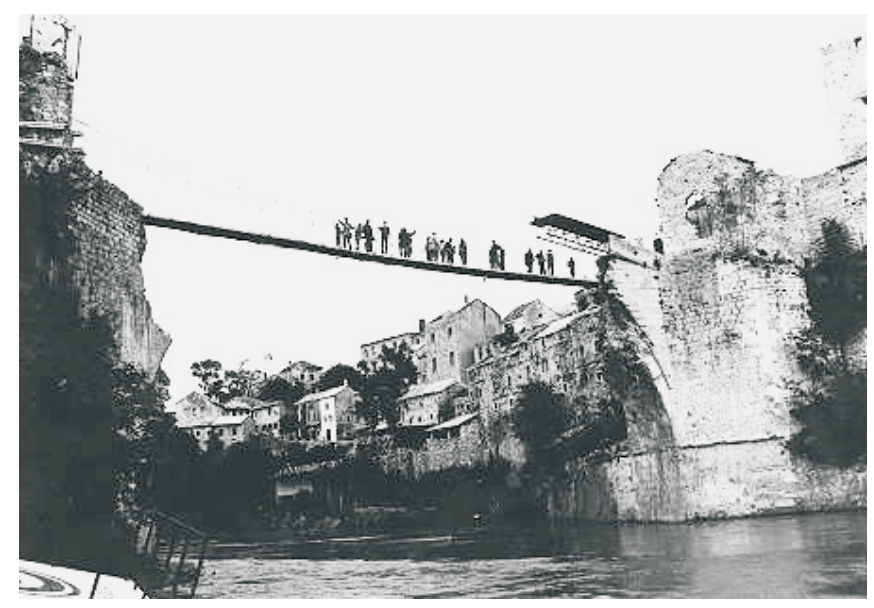

Fig. 3: Destroyed bridge - south elevation

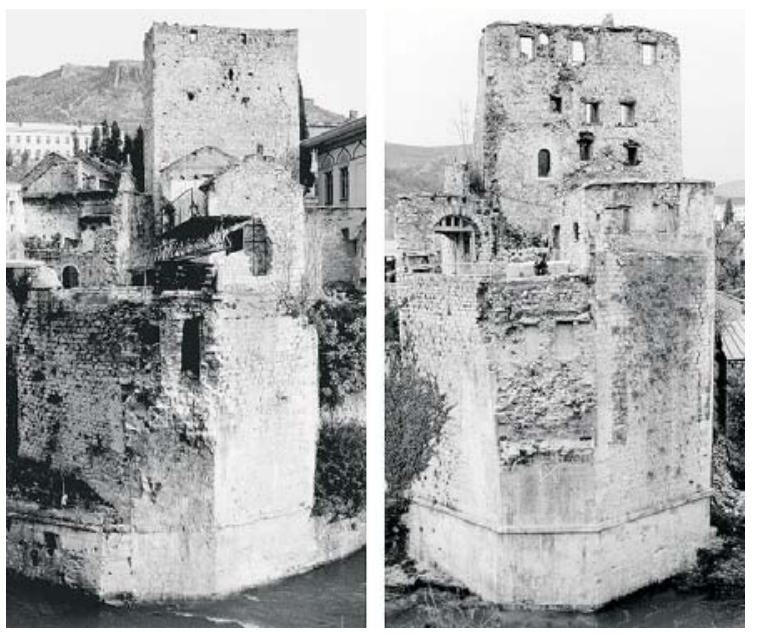

Fig. 4: Destroyed bridge - east and west elevation 


\section{Destruction}

The Old Bridge of Mostar was destroyed in November 1993 by shelling during the war. The shelling was captured on film and some technical data and observations have been gathered on the basis of this documentation.

An analysis of the remaining portions of the bridge near the east abutment, shows thet there was greater surface deterioration on the north side than on the south side. The shelling came from the south side, and hit mostly the south east portion of the bridge over the arch reins: the most extensive remaining portions of the bridge were located on that side. Shootings was also directed at the north elevation during other attacks, and for this reason the bridge was protected by tyres, ( the temporary structures over the footpath were intended to protect people from gunfire). Shelling was directed at a single spot in order to destroy the structure with the minimum numbers of shells. The structure was divided into two main parts: a small part below the arch reins on the east bank, and a big part which was totally blown into the river.

\section{Reconstruction of the Old Bridge}

The initiative to rebuild the Old Bridge began soon after the war. As the bridge was one of the masterpieces of Ottoman architecture, the Turkish government offered to cover all the expenses for the reconstruction. However, what the people of Mostar needed most was to reconstruct the broken bridges between themselves. The city government decided to use this reconstruction to heal the war wounds, and to use international experts to promote the importance and value of this project.

A Project Coordination Unit (PCU) was formed by the World Bank, UNESCO and City of Mostar, as a specialized agency responsible for performing professional and other tasks to coordinate the project to the build the Old Bridge and other structures within the Pilot Cultural Heritage Projects for Bosnia and Herzegovina.

\section{Materials used in reconstructing the arch}

- most of the stone elements of the bridge including the vault, cornices, spandrels and parapets, were made in tenelija stone (Category I), which is a local oolithic limestone rock of light and warm colour and high porosity, resistant to compressive strengths of about $20 \mathrm{MPa}$; (from the Mukoša quarry);

- the pavement and the stone slabs over the lightening voids were in krecnjak stone, a light-colour hard and resistant marble-like limestone;

- the metal connectors, cramps and dowels, were in forged iron as was the fence;

- lead was used for the connectors and for assembling the fence;

- mortars of different types and compositions were found all over the structure. Terra rossa - red colour aggregates with a remarkable content of bauxite were settled in a layer beneath the pavement.

\section{Dismantling the remenants bridge}

One of the first tasks of the contractor for the actual reconstruction of the bridge was to prepare the Site around the Old Bridge. The erection of the scaffolding for the side walls began on 12. 07. 2002. This scaffolding was necessary for the repair works on the abutment walls in order to provide a solid base for the arch.

After determining the best possible position for placing the main crane, it was necessary to investigate whether the soil beneath it could bear the weight. After the necessary drillings, crane foundations were built, and few days later the crane came into use.

The first actual task on site was to remove the existing parts of the arch. The pavement on the right side of the bridge began to be dismantled on 31.10.2002. Each pavement stone had previously been marked, documented and

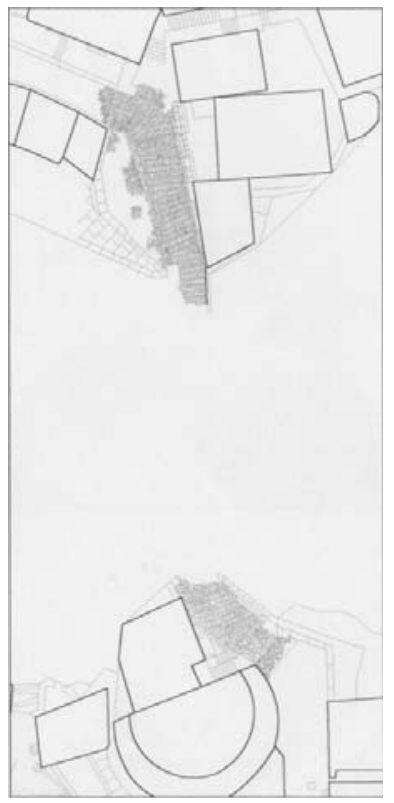

Fig. 5: Plan view after destruction

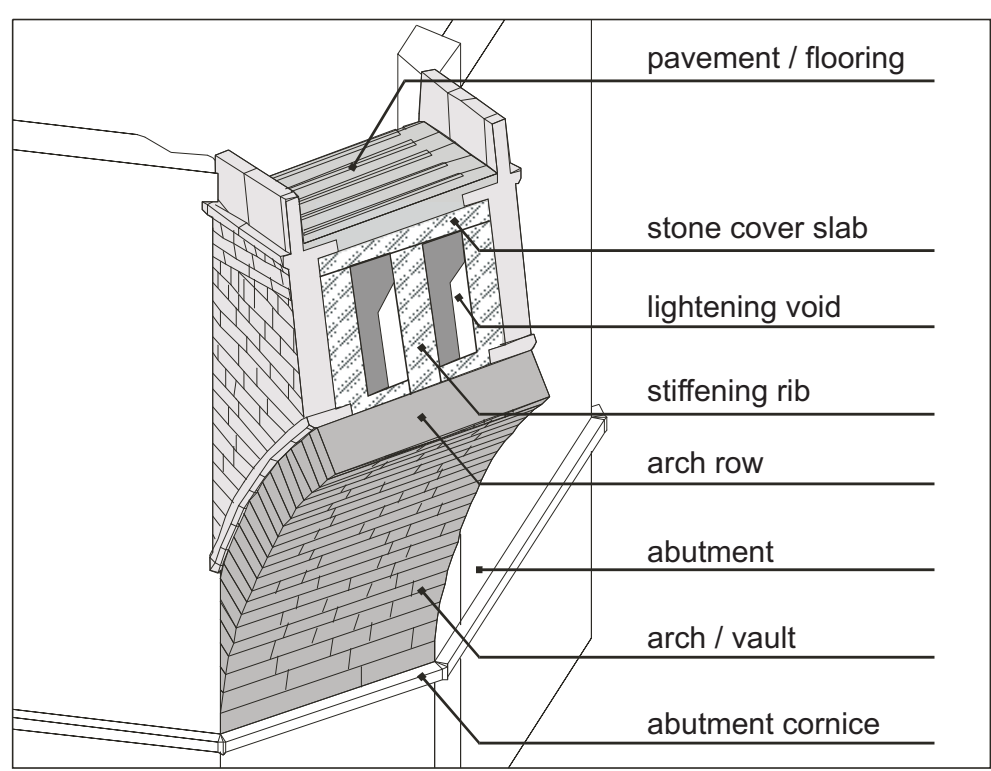

Fig. 6: Structural elements of the bridge 


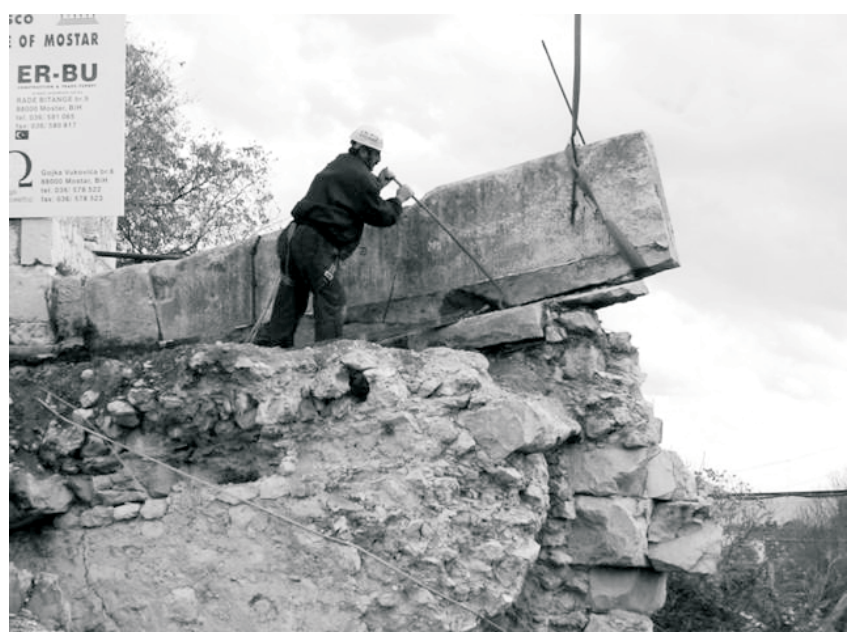

Fig. 7: Dismantling the remnants of the bridge on the south east side

measured. Due to its irregular surface and its particularly visible position, the pavement was one of the most delicate dismantling and rebuilding tasks. It was a very delicate job, because it was important to return the largest possible number of stones to their original place. The workers, using hand tools, separated each stone individually from the mortar, silicon and soil.

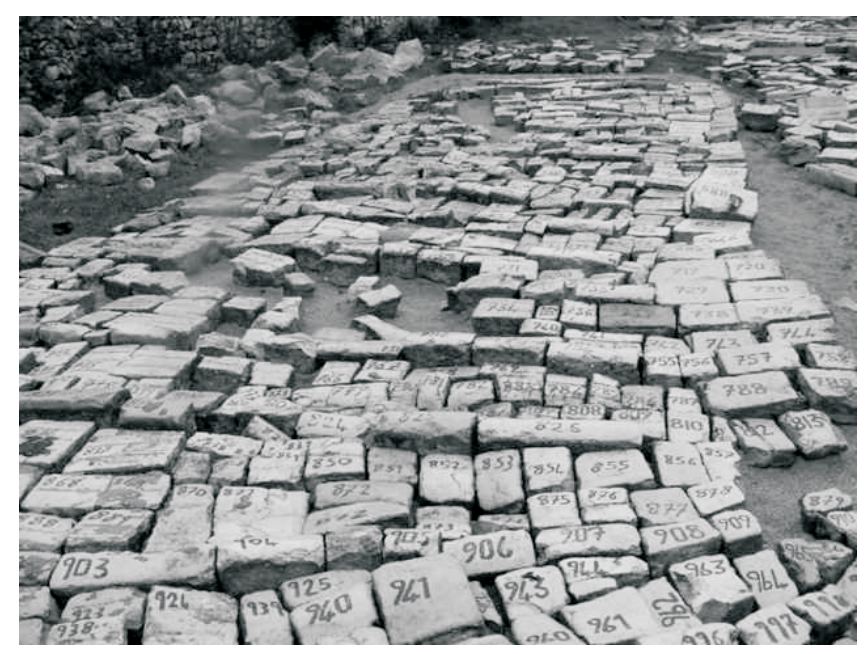

Fig. 8: Pavement stones in their new location

On $19^{\text {th }}$ November 2002, the remnants of the bridge on the left bank of the Neretva began to be dismantled. This task was very delicate because the console of the bridge that remained after demolition was in very bad condition. Structural fractures were visible. There was no solid support under this part of the bridge for auxiliary structure, which made the job even more difficult. Each dismantled stone was marked and taken away.

\section{The centering}

One of the most important elements in the reconstruction of the Old Bridge was the centering. Because of the unpredictable winter and spring levels of the Neretva, the main steel grids were place above the point of highest possible flow.
It was decided that the entire structure, up to the final wooden bedding, would be made of steel, to ensure maximum precision in imitating the former arch. This was essential, because the tolerance was less than $\pm 1 \mathrm{~cm}$ from the recorded coordinates of the bridge before destruction.

To facilitate movement of people and materials while the centering was being erected, Neretva was temporarily spanned by a pontoon.

After the concrete pillars had been produced, preparatory works began on lifting the transversal grids. Between the pillars on both sides, auxiliary steel structures were placed for lifting the grids.

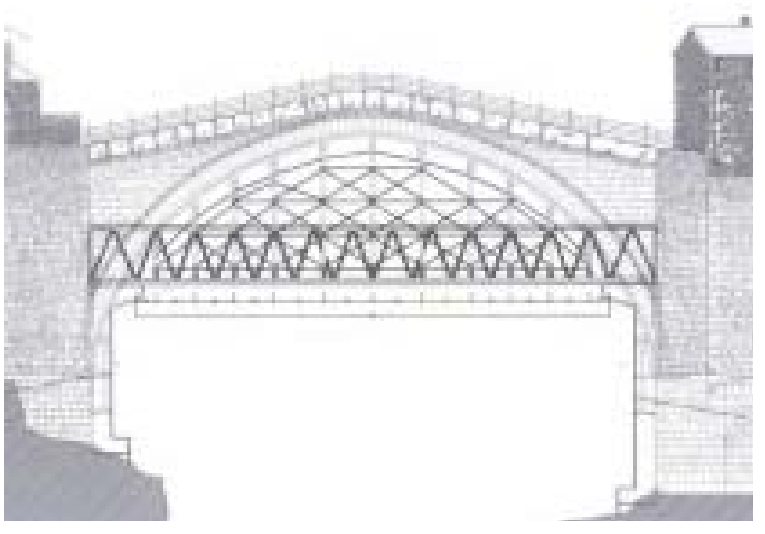

Fig. 9: South elevation of centring

Transversal girders were mounted on the main steel truss structure (HEB 40), and feet were welded on to it for mounting the heavy steel scaffold f 159/150 mm.

After the heavy scaffold, which followed the arch, had been mounted it was consolidated with a light scaffold $\mathrm{f} 48$ $\mathrm{mm}$. Height regulators were mounted on the heavy scaffold, and beams of dimensions $24 / 20 \mathrm{~cm}$, so called covers, on which six wooden semi-circular planks were placed. The final phase was to prepare the floor for the bridge stones.

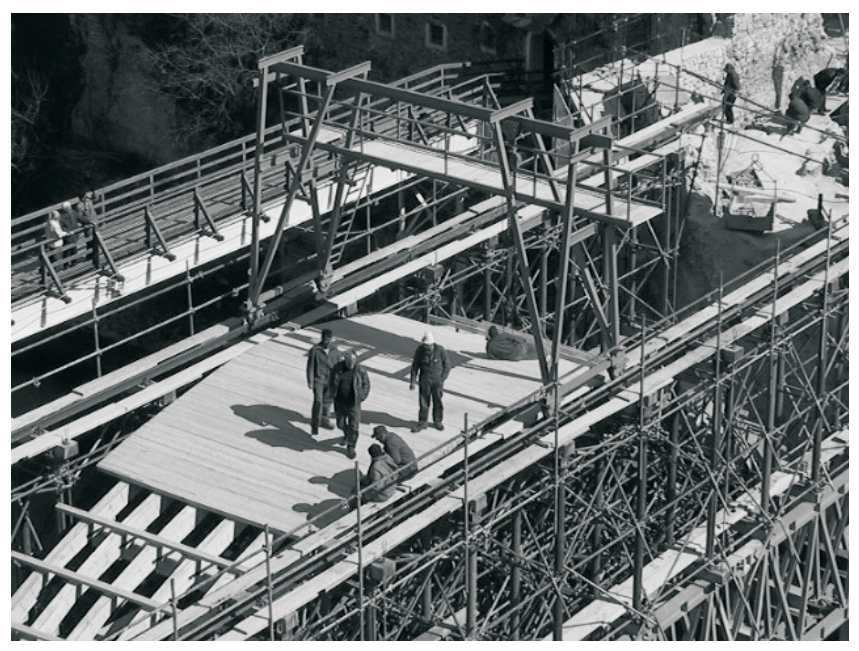

Fig. 10: Portal crane

While the centering was being mounted, the portal crane structure was also being set up. The portal crane was needed to ensure that the arch was assembled with precision. 


\section{Assembling of the voussoirs}

The arch voussoirs are the elements of the load bearing arch, and are therefore the most important portion of the bridge. Many reinforcing devices were used to ensure efficient joint connections. To better understand how voussoirs were assembled, it should be taken into account:

- the load bearing arch was composed of 111 rows of voussoirs $395 \mathrm{~cm}$ in thickness;

- each row contained 2-5 voussoirs (normally 3-4);

- rows of voussoirs were mounted from both sides of the bridge;

- the joints of voussoirs belonging to one row were shifted in relation to the preceding row, (as in ordinary masonry work);

- a mortar layer was used to join adjacent voussoirs, (as in ordinary masonry work);

- additional metal elements were mounted across the joints;

- three different metal strengthening devices were used for the arch stones: dowels, side cramps and extrados cramps;

- metal elements, with purpose-built carvings to host them, had quite variable dimensions and sizes in the bridge structure.

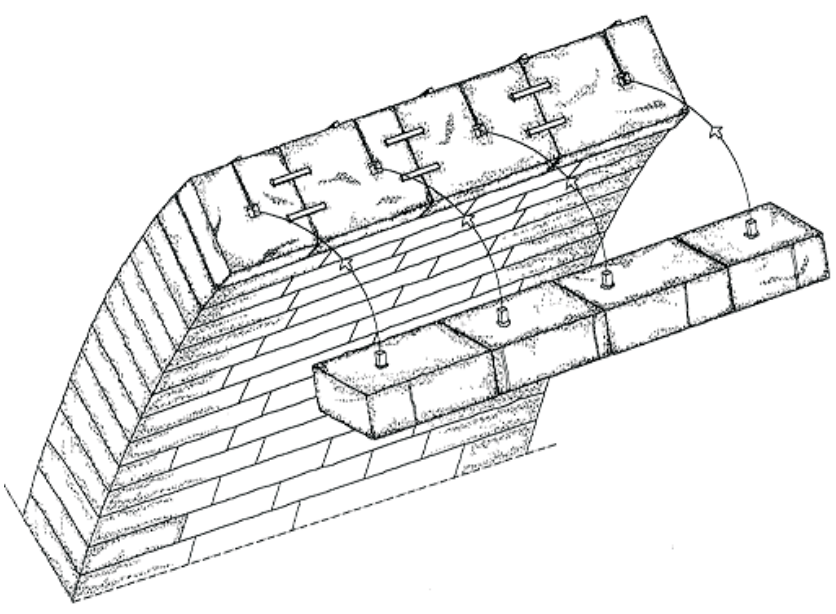

Fig. 11: Assembling the load bearing arch

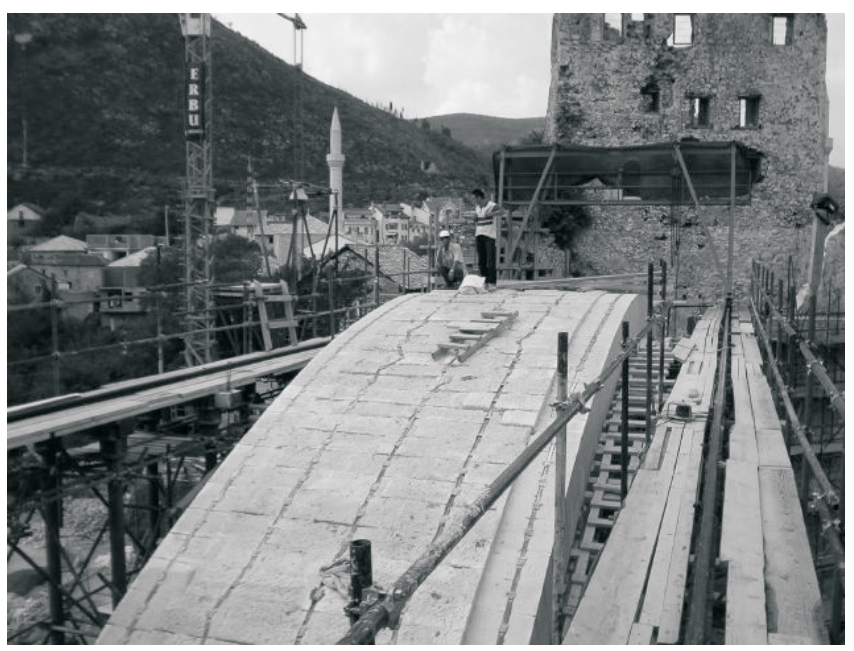

Fig. 12: Load bearing arch completed

\subsection{Dowels in the arch stones}

Each arch stone was linked to one or two voussoirs in the preceding row by one or more metal dowel. Dowels were applied to the stone blocks in specially carved slots (holes), and melted lead was poured into the slots to connect the metal and stone elements.

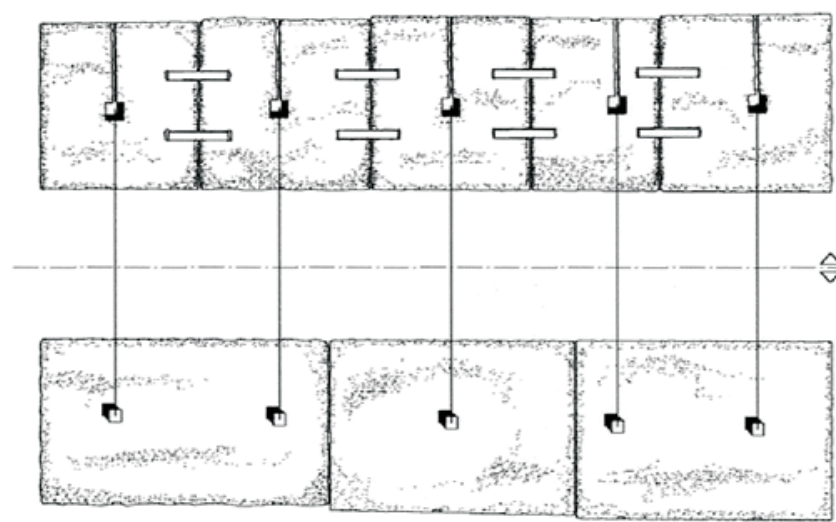

Fig. 13: Positions of the dowels in a typical voussoir row

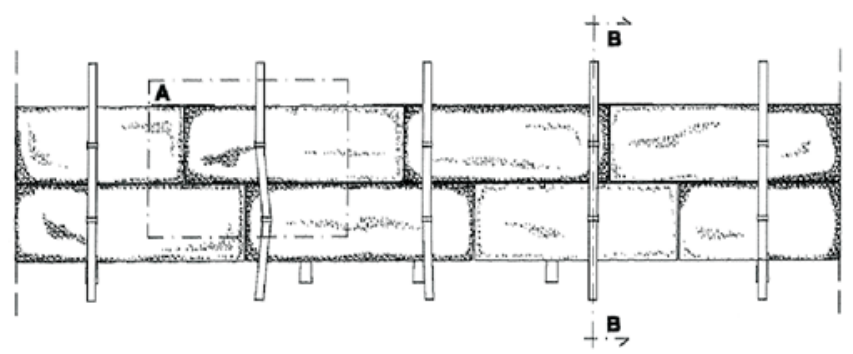

Fig. 14: Typical placing of the cramps in the extrados

\subsection{Side cramps in the arch stones}

The adjacent voussoirs of each row were connected with double side cramps crossing the joints; again, the cramps were linked to the stone with melted lead, poured into specially constructed slots. The side cramps were quite regular, of similar shape and size, and there were fewer variations along the load bearing arch.

\subsection{Extrados cramps in the arch stones}

Extrados cramps were located over the extrados of the load bearing arch: there were five rows of cramps that running in parallel directions following the curved profile. The extrados cramps acted like tying chains, or at least they were conceived with this purpose, being one adjacent to the other. These cramps were different from all the others that have been found in the bridge stone structure, because they were dimensioned exclusively according to the arch stone measures: where one cramp ended, another started, sharing the same stone-slot to allow continuity of the tying action.

\subsection{Assembling the lower cornices}

The lower cornices are located directly above the extrados of the load bearing arch, jutting out from the vault profile to 
protect the structure. Below the lower cornices, being assembled on a curved profile, required special care during the adjusting procedures, and were anchored to the arch with a mortar layer. On top side of the cornices, across the joints, a single row of cramps was placed approximately along the longitudinal axe of the stone elements.
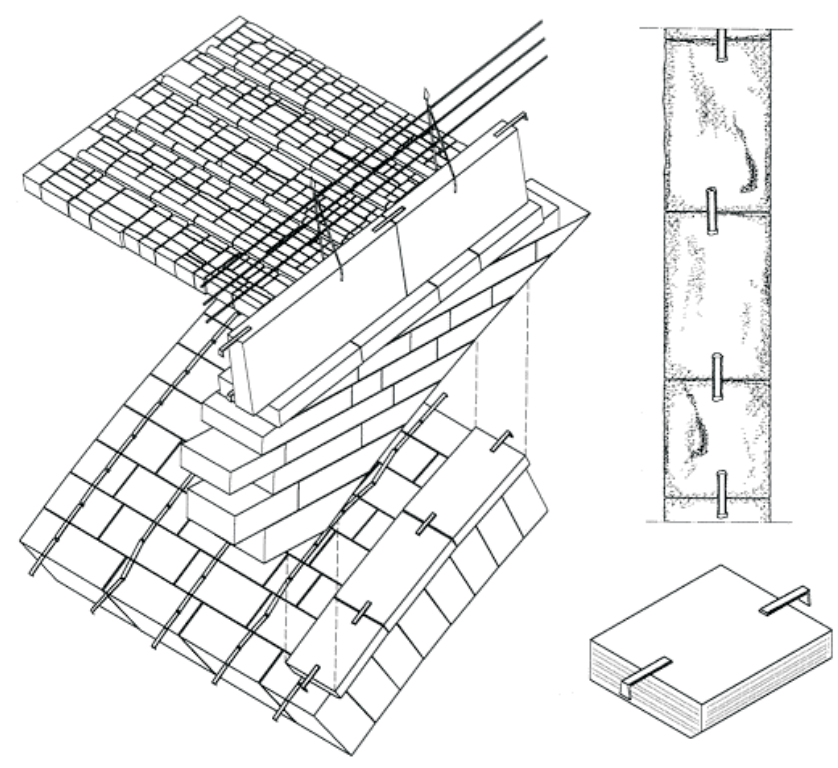

Fig. 15: Scheme of cornice

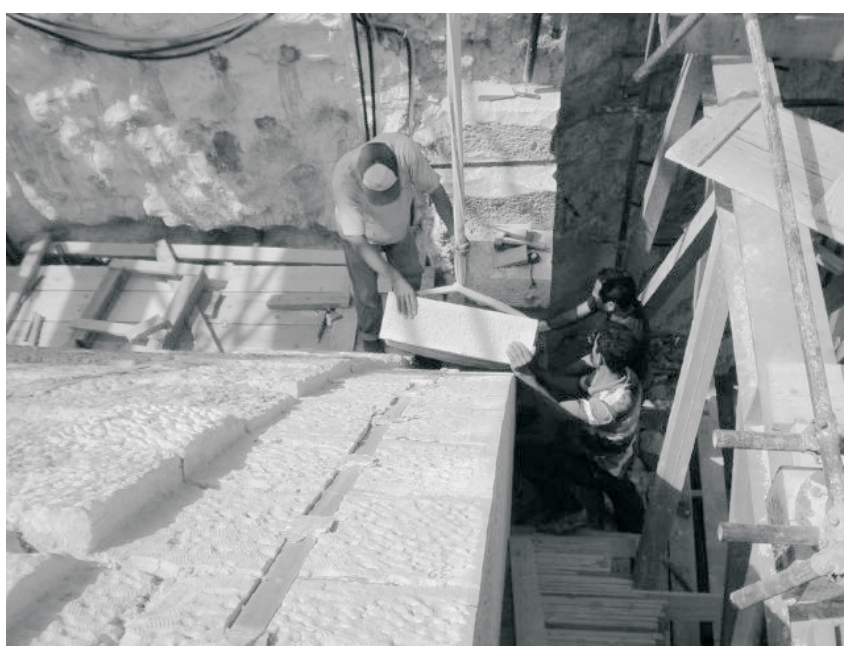

Fig. 16: Assembling the cornices

\subsection{Spandrel stones assemblage}

The spandrel walls were made in ordinary ashlar masonry work with thin mortar joints. On the top side of the spandrels, across the joints, a single row of cramps was placed approximately along the longitudinal axis of the stone elements, however the variability of this parameter was quite high, being related to the thickness of the ashlar. The stone block rows were sometimes assembled with a slight gradient, perhaps due to ordinary construction imperfections or in order to optimise of the connection with the load bearing arch.

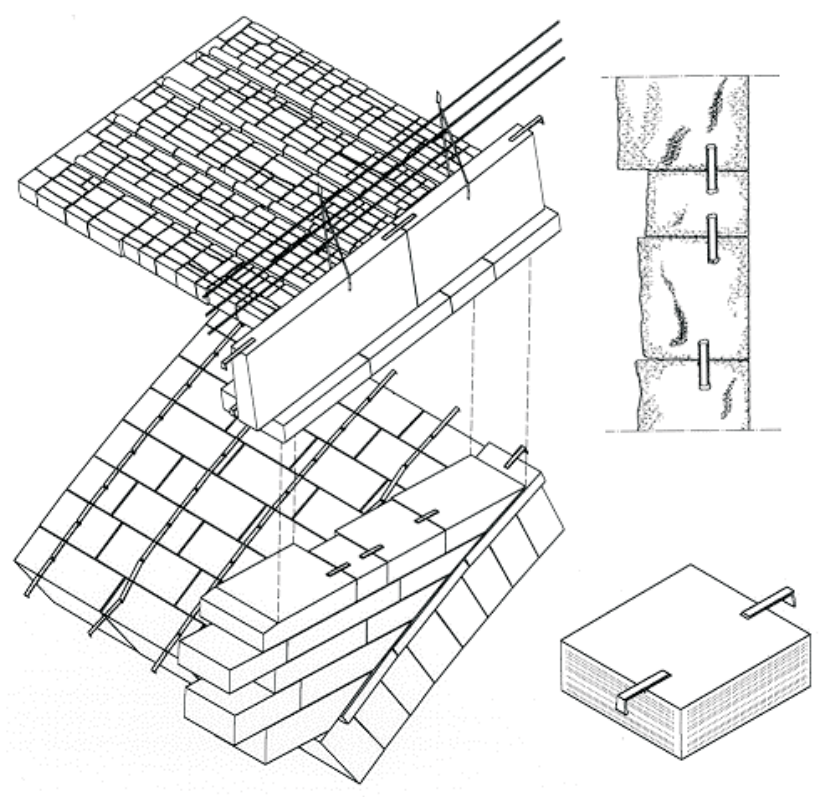

Fig. 17: Scheme of spandrel stone assembly

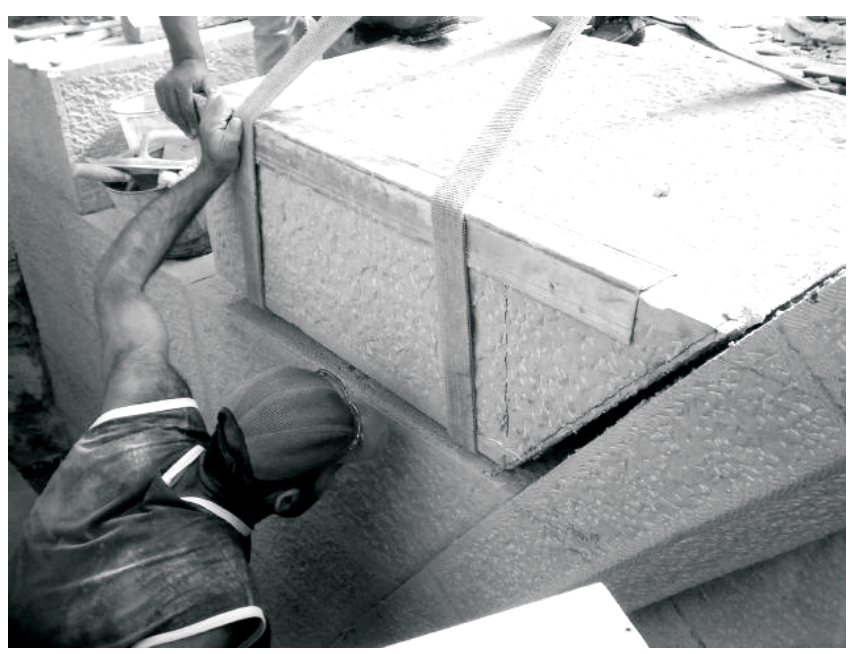

Fig. 18: Assembling the spandrel stones

\subsection{Assembling the upper cornices}

The upper cornices were placed very accurately on a mortar layer over the spandrel walls, to ensure that the top was tangent to the lower cornice, and at the same time, that thecornices were jutting out from the spandrel wall profile to protect them from rainwater. The upper cornices were generally bigger than the lower cornices, and perhaps for this reason, had two rows of cramps instead of one. The cornices were provided with slots and channels that were used to host the dowels of the parapets.

\subsection{Assembling the parapets}

The parapets were assembled over the upper cornices with a mortar layer and with dowels, that previously had to be mounted on the lower edge of the parapet. They were inserted in the slots of the upper cornices. The whole was linked by pouring melted lead in the specially carved channels over 


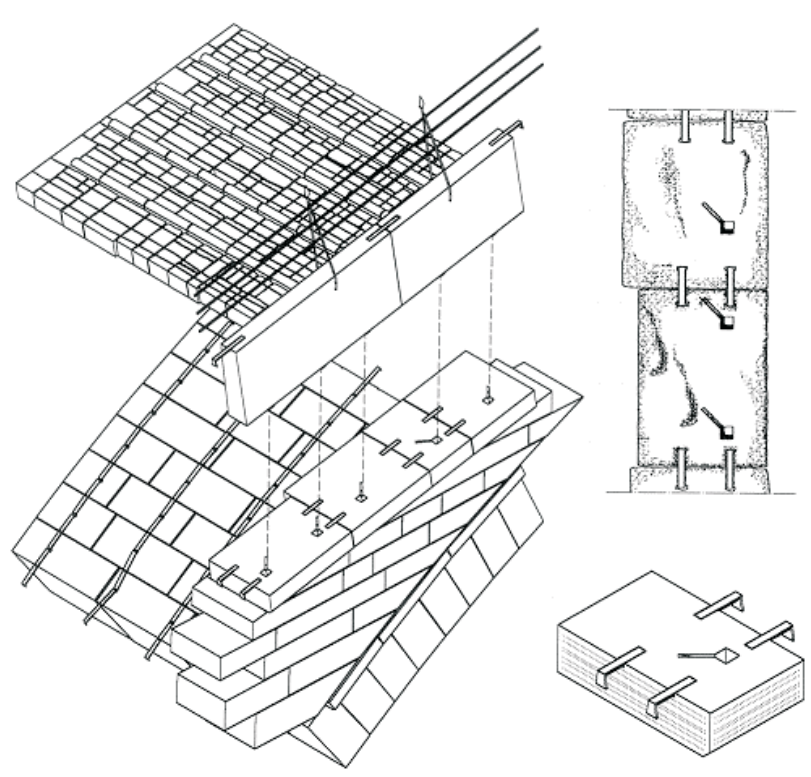

Fig. 19: Scheme of the upper cornice assembly

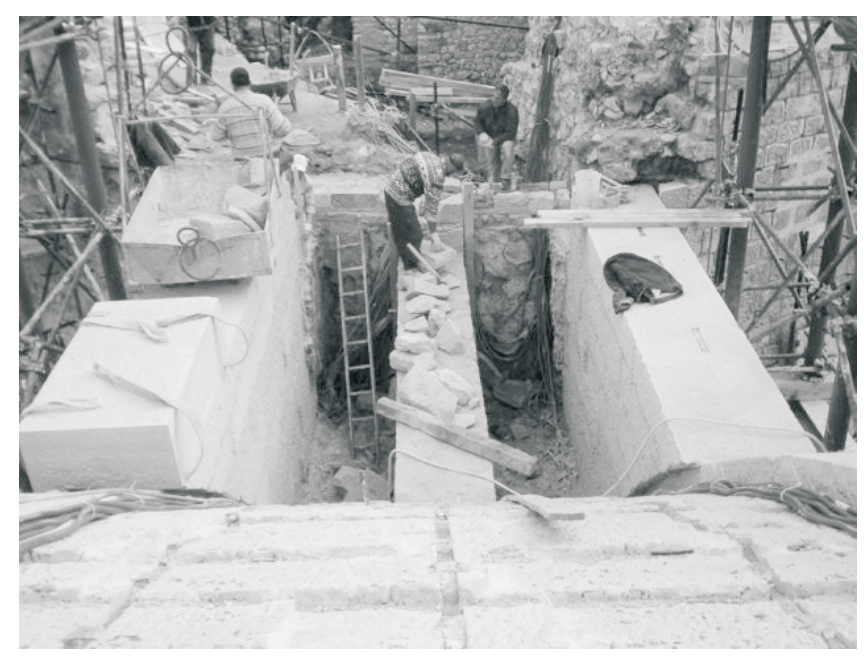

Fig. 20: Assembling the upper cornice

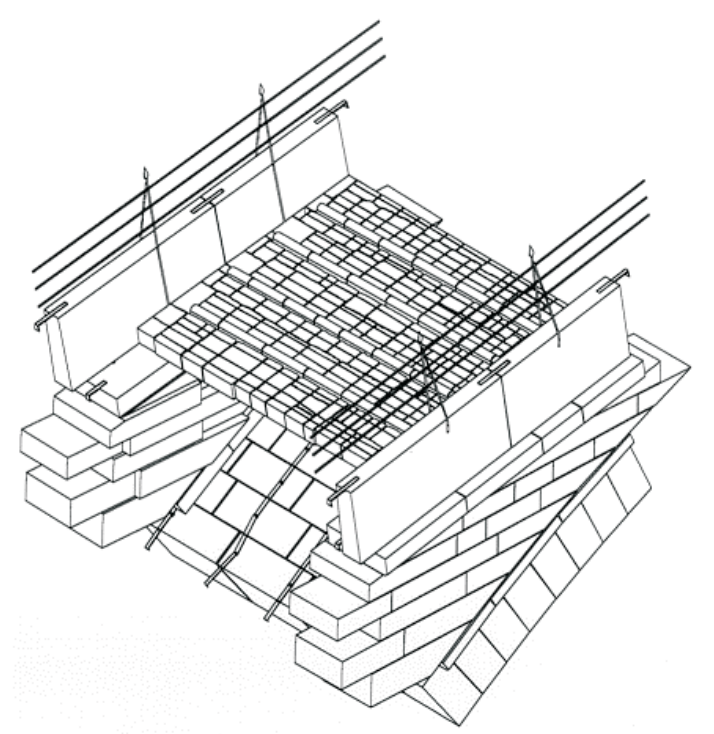

Fig. 21: Scheme of the metal elements in the parapets and the fence

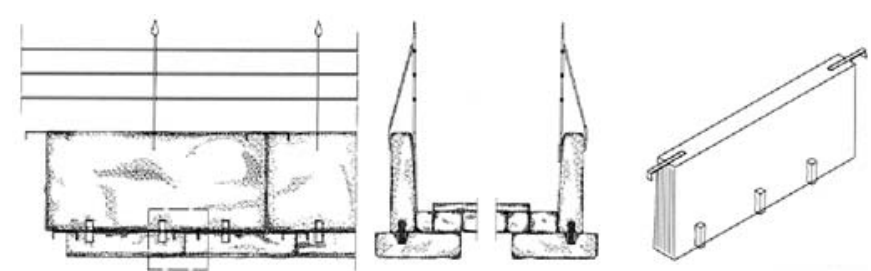

Fig. 22: Scheme of the parapets assembly

the cornices. On the top edge of the parapet some other cramps were placed across the side joints (also linked with mortar). It seems that the parapets towards the top of the bridge were intentionally assembled slanting slightly outwards, perhaps in order to create an optical effect that could give the impression of a wider footpath.

\subsection{Assembling of the fence}

The fences had most probably been assembled in a subsequent period to protect people from falling. The fences were made of forged iron.

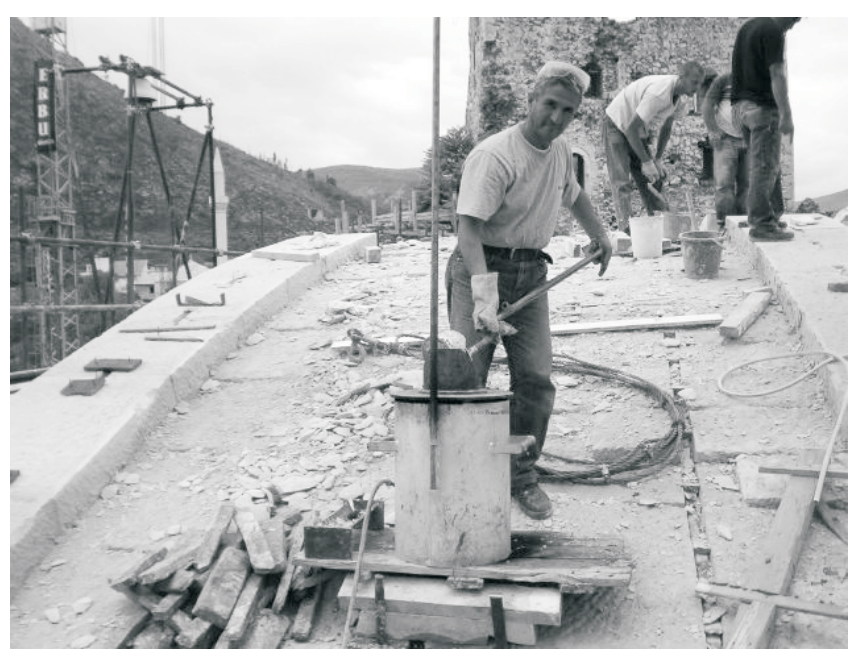

Fig. 23: Lead melting can

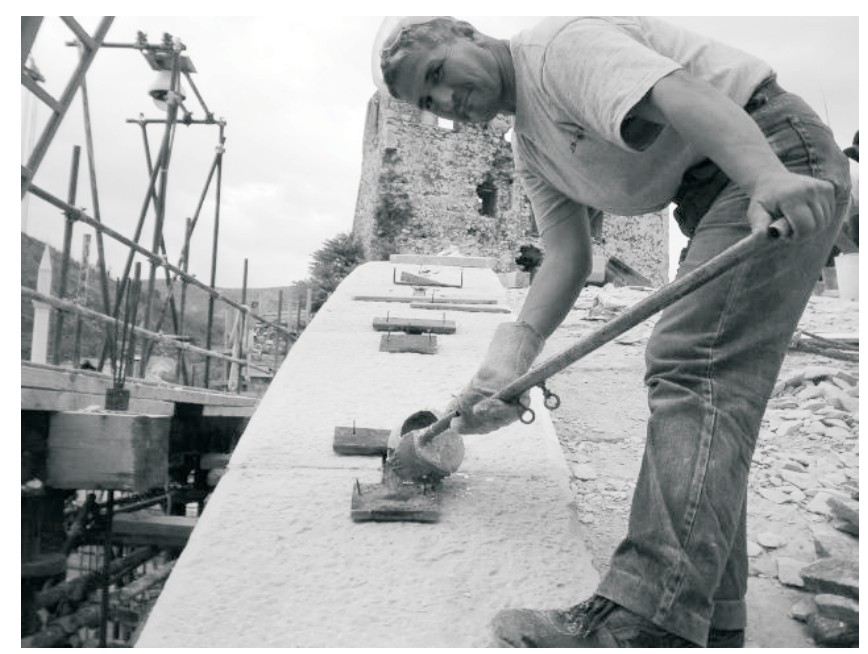

Fig. 24: Pouring the led 


\section{Lead pouring}

One of the most important materials used in constructing the bridge was lead. The bridge itself was an organic structure, capable of resisting various kinds of pressures: strong wind, the river, earthquakes, etc. This kind of flexibility was achieved with the use of metal cramps and dowels, fixed within the stone cavities with lead. Lead was melted at $380-390{ }^{\circ} \mathrm{C}$, in a special heater, and poured into the hole using a small can.

One of the most important and most delicate procedures while building the bridge was pouring the lead into the voussoir stones. Lead was poured through channels into the "hidden" (already inserted) dowels between the rows of the arch. The channels had to be dry and clean, and the lead had to be poured at the optimum rate. This dangerous procedure was performed with $100 \%$ success.

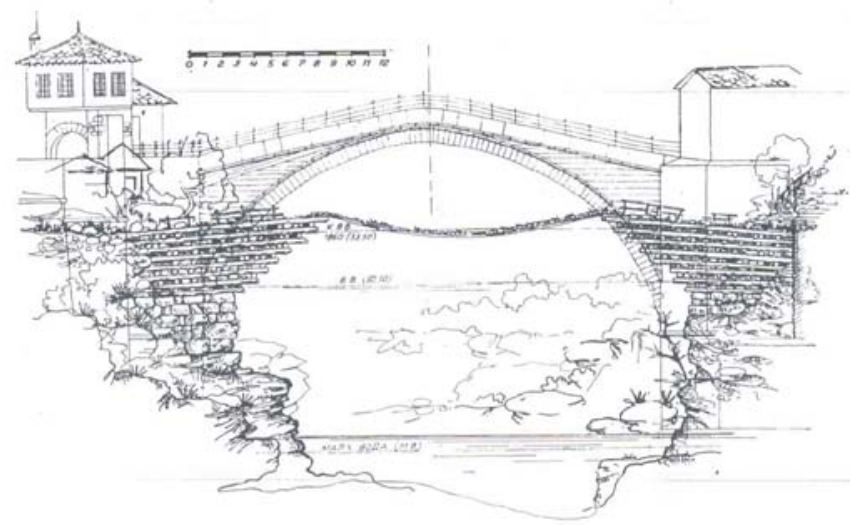

Fig. 25: Presumed appearance of the suspension bridge, by Prof. Gojkovic

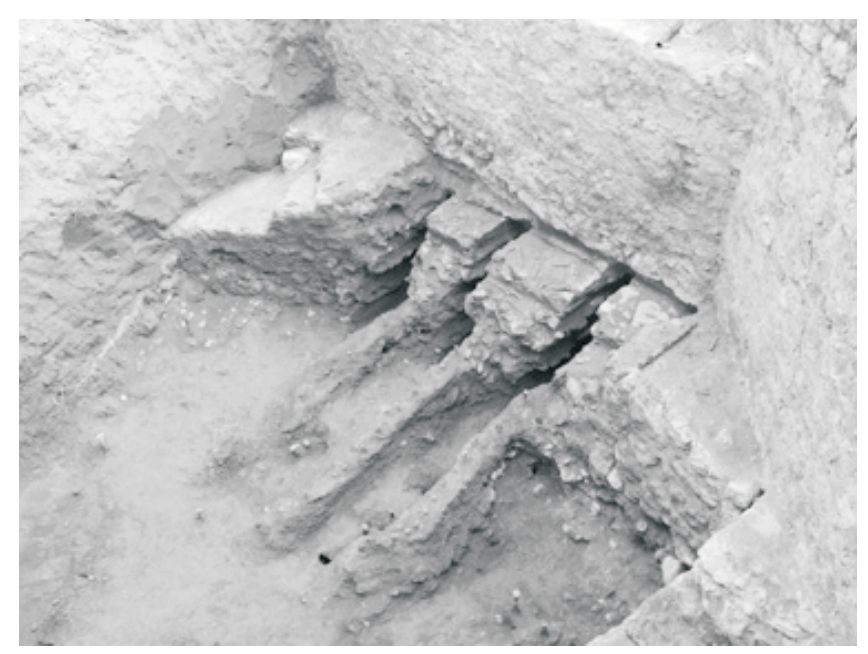

Fig. 26: Traces of the beams for the suspension bridge

\section{Archaeological report}

After a sonar investigation of the towers, which was carried out at the end of 2001 and the beginning of 2002, archaeological work on both sides of the arch restarted in October 2002.
The archaeological explorations were finished on $6^{\text {th }}$ March 2003, when the excavations reached the rock which is also the last context established under ordinal number 5. Altitude K-5 on the left bank was 46.90, while on the right bank it was 46.50 in the southern part of the quadrant and 46.30 in the northern part.

The archaeological findings were very interesting on both sides. Several masonry structures were found, some of which can be assigned to previous bridges. Most probably two bridges had existed at the same spot before the Old Bridge. These masonry structures were on both sides of the Neretva and they developed at the same time (the objects discovered on one side were also found on the other side).

In the springer the excavation reached the sterile rocky mass layer. A layer of earth more than $8 \mathrm{~m}$ in height which additionally burdened the spandrel walls was excavated, so the walls will no longer be burdened. These excavations enable high quality restoration of the foundation walls on both sides.

\section{Recorded findings}

The oldest finds date from the $15^{\text {th }}$ century. The archaeological finds were recorded in detail in all layers and documentation was made. This dealt with all recorded archaeological findings, contexts, photos and the plan view with cross-sections, and it will be published in a scientific journal.

The finds were sent to Croatia for restoration: the metal items to Museum of Croatian Archaeological Monuments in Split, and the wood items to the Croatian Restoration Institute. After treatment they will be returned and placed in the future archaeological museum.

About 200 pieces of pottery were found on the site - dating form the $15^{\text {th }}$ to $20^{\text {th }}$ century, about twenty stone and one metal cannon balls, about 250 metal wedges from the structure of wooden bridge, one copper coin and several mediaeval tools.

These studies, which will be continued, have integrated and modified the image of the site development. They have also changed the image of all recent preliminary reports. These finds have changed the flow of construction, and have provided more elements for precise dating of specific walls.

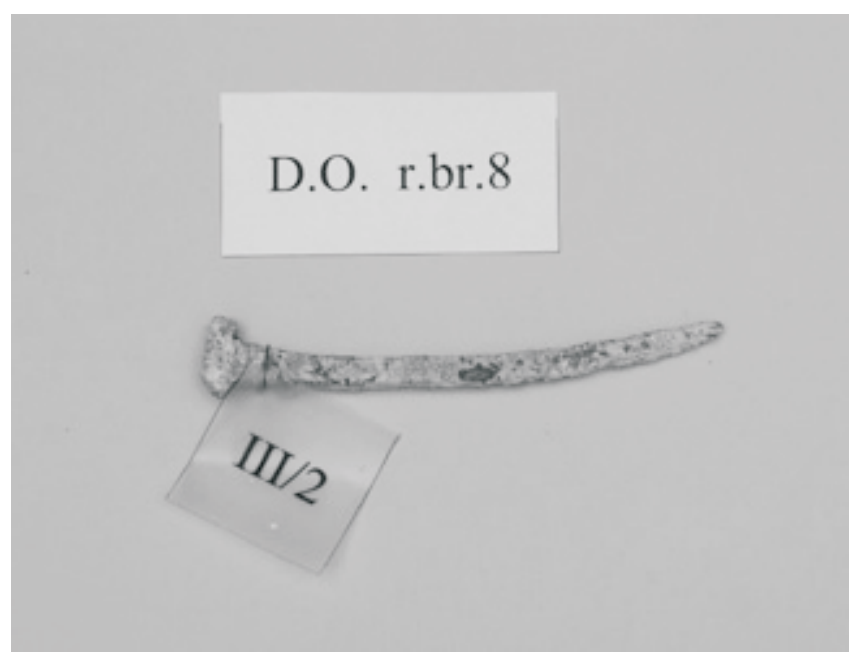

Fig. 27: Huge iron nail from the suspension bridge 


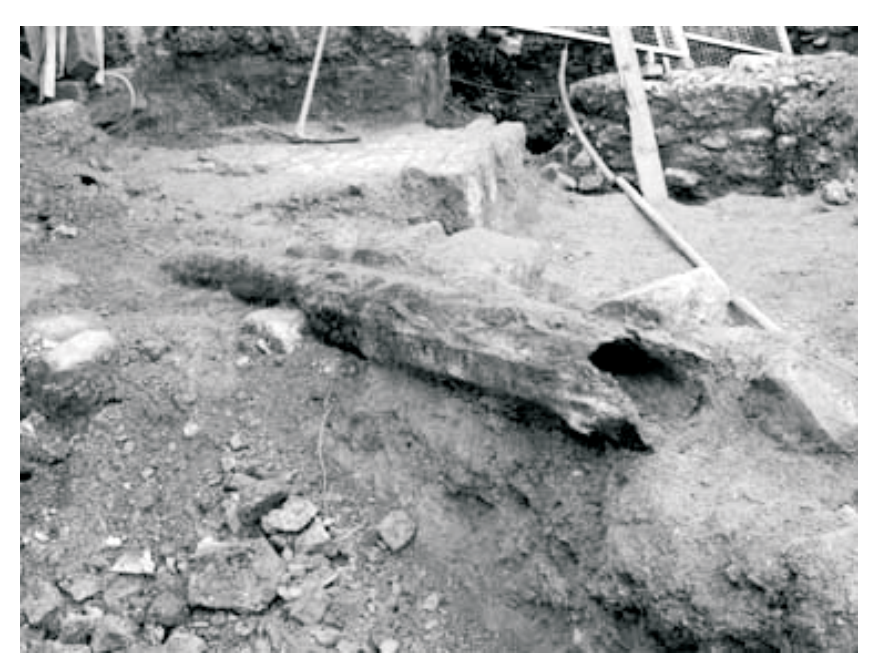

Fig. 28: Wooden pipe covered in terra rossa

\section{Conclusion}

Reconstruction of the Old Bridge of Mostar was a pioneer project in the field of reconstruction. While performing this task, we faced many problems and difficulties on site, and this gave us even more reason to respect the ancient builders. We can only imagine how hard it was to build a masterpiece like this, without any present-day equipment or technology. This reconstruction produced many outcomes: experts and the scientific world gained new insights into construction methods, materials and structures; the word and mankind regained a rare and beautiful monument for the UNESCO list; and last, but certainly not least, the people of Mostar proudly have regained their symbol of peace, multiethnic and multireligious coexistence.

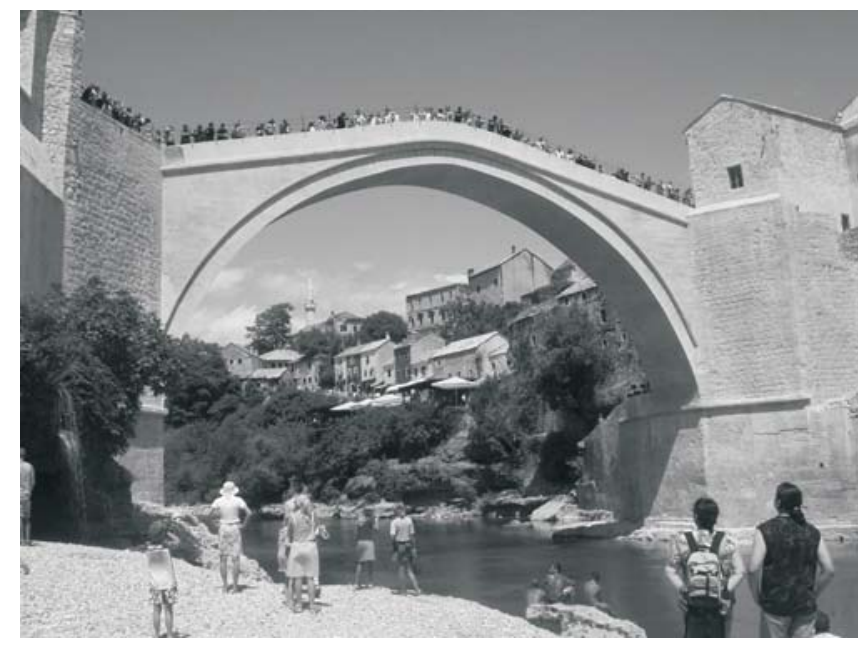

Fig. 29: New Old Bridge today

\section{References}

[1] Celic, Dz., Mujezinovic, M.: Stari mostovi u Bosni I Hercegovini. Sarajevo: Sarajevo - Publishing, 1998, p. 228-246.

[2] Mutevelic, I.: Mostar. Mostar: Prva knjizevna komuna, 1982.

[3] Romeo, M. et al.: Architectural Report, Phase B. Florence: General Engineering, 2000.

[4] Krsmanovic, D., Dolarovic, H., Langof, Z.: "Sanation and Conservation of the Old Bridge at Mostar." In: Nase starine XI. Sarajevo: Zavod za zastitu spomenika kulture S. R. Bosne I Hercegovine, 1967. p. 5-23.

Ing. arch. Maja Popovac

phone: +38736566112

mobile: +38761204809

e-mail:popovac@hotmail.com

K. M. V. Humskog 33

88000 Mostar, Bosnia and Herzegovina 